\title{
HIPERDONTIA: RELATO DE CASO COM 8 ELEMENTOS SUPRANUMERÁRIOS
}

\section{HYPERDONTIA: A CASE REPORT WITH 8 SUPERNUMERARY TEETH}

\author{
Tiago Estevam de Almeida * \\ Jesus Saavedra Junior * \\ Paulo Yataro Kawakami … \\ Carla Andréa Palis $\cdots \cdot$ \\ Pérsio Bianchini Mariani ${ }^{\cdots * * *}$ \\ Alexandre Meloti Dottore **....
}

\begin{abstract}
RESUMO
O termo hiperdontia designa os dentes que estão em excesso na arcada dentária. Sabe-se que a arcada dentária normal é constituída de vinte dentes decíduos e de trinta e dois permanentes. Estes dentes podem ser classificados como dentes supranumerários rudimentares, quando não apresentam forma anatômica usual dos dentes presentes na região em que foram encontrados, ou suplementares quando apresentam a forma dos dentes da região. Normalmente são diagnosticados em radiografias de rotina e o tratamento é eminentemente cirúrgico. O presente trabalho tem como objetivo fazer um relato de caso de hiperdontia com oito elementos supranumerários.
\end{abstract}

DESCRITORES: Dente supranumerário • Diagnóstico bucal.

\section{ABSTRACT}

The term hyperdontia means teeth that are in excess in the dental arch. It's known that the normal dental arch consists of twenty teeth and thirty-two permanent. These teeth can be classified as rudimentary supernumerary teeth, if not present the usual anatomical shape of the teeth in the region where they were found, or when additional are in the form of teeth in the region. They are usually diagnosed on routine radiographs and surgical therapy. This work aims to make a case for hyperdontia eight supernumerary elements.

DESCRIPTORS: Tooth, supernumerary • Diagnosis, oral.

* Mestre em Cirurgia Bucomaxilofacial pela Universidade de São Paulo - USP. Residência em Cirurgia Bucomaxilo facial pelo HSPE/FMO-SP, Especialista em Implantodontia pela CIODONTO. Cirurgião Bucomaxilofacial do HMU de Guarulhos. Aluno do curso de graduação em Medicina da Universidade Cidade de São Paulo - UNICID-SP.

** Cirurgião Dentista com Residência em Cirurgia Bucomaxilofacial pelo Hospital Municipal Tatuapé-SP - Dr. Carmino Caricchio.

*** Professor dos cursos de Especialização em Implantodontia da CIODONTO/ADOCI, APCD Saúde e da Universidade de Uberaba. Consultor da 3i. Doutorando em Periodontia pela Universidade de Guarulhos - UNG. Mestre em Implantodontia pela UNISA. Especialista em Cirurgia Bucomaxilofacial e Implantodontia.

**** Cirurgiã Dentista pela Universidade de Uberaba - UNIUB com Especialização em Ortodontia e Ortopedia Facial pela Universidade de Guarulhos UNG.

***** Coordenador do Setor de Cirurgia Bucomaxilofacial do HMU de Guarulhos. Mestre pela Fundação Antônio Prudente-Hospital do Câncer A. C. Camargo. Membro Titular do Colégio Brasileiro de Cirurgia Bucomaxilofacial. Aluno do curso de graduação em Medicina da Universidade Cidade de São Paulo - UNICID-SP.

****** Especialista em Cirurgia Bucomaxilofacial pela Universidade de Guarulhos - UNG e em Implantodontia pela CIODONTO. 


\section{N T R O D U Ç Ã O}

O termo hiperdontia designa os dentes que estão em excesso na arcada dentária (Bertolho et al 2000). Sabe-se que a arcada dentária normal é constituída de vinte dentes decíduos e de trinta e dois permanentes (Schneider e Sampson ${ }^{2}$ 1997). Esses dentes podem ser classificados como dentes supranumerários rudimentares, quando não apresentam forma anatômica usual dos dentes presentes na região em que foram encontrados, ou suplementares quando apresentam a forma dos dentes da região (Campos et al. ${ }^{3}$ 2002). Já Bhaskar ${ }^{4}$ (1989) definiu como acessórios os dentes que não apresentam forma normal, enquanto que o termo supranumerário é usado para os que imitam a forma normal. Esses dentes recebem várias denominações, de acordo com a localização. Se estiverem entre os incisivos superiores, são chamados de "mesiodentes", se na distal dos terceiros molares, "quartos molares", se na região de pré-molares, terceiros prémolares e em relação vestíbulo-lingual aos molares, são chamados de "paramolares".

Destes dentes supranumerários o mais comum é o "mesiodente", seguido do quarto molar superior. Além destes, os "paramolares" superiores, pré-molares inferiores, incisivos laterais superiores, incisivos centrais inferiores, pré-molares superiores e quartos molares inferiores são encontrados com frequência. Também a literatura afirma que maxila é cerca de nove vezes mais afetada que a mandíbula e os dentes supranumerários são mais comuns na dentição permanente (Snafer et al. ${ }^{5}$ 1987).

Grande parte dos autores acredita na teoria de que os dentes supranumerários são formados e desenvolvidos como resultado da proliferação horizontal ou da hiperatividade da lâmina dentária, tanto decídua quanto permanente (Spauge $^{6}$ 1973). São encontrados em sua maioria no gênero masculino em numa proporção de 2:1 quando comparados com o feminino (Duarte e Gomes ${ }^{7}$ 1995), sendo que sua prevalência varia de $0,1 \%$ a $3,8 \%$ (Pindborg ${ }^{8}$ 1970).

Esses elementos dentários podem se manifestar de maneira isolada ou múltipla, unilateralmente ou bilateralmente, inclusos ou parcialmente ou totalmente erupcionados, impactados ou não (Yusof ${ }^{9}$ 1990). Normalmente são diagnosticados
ALMEIDA TE

SAa VEDRA JUNIOR S

KAWAKAMI PY

PALIS CA

MARIANI PB

DOTTORE AM

HIPERDONTIA:

RELATO DE CASO

COM 8 ELEMENTOS

SUPRANUMERÁrios

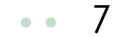

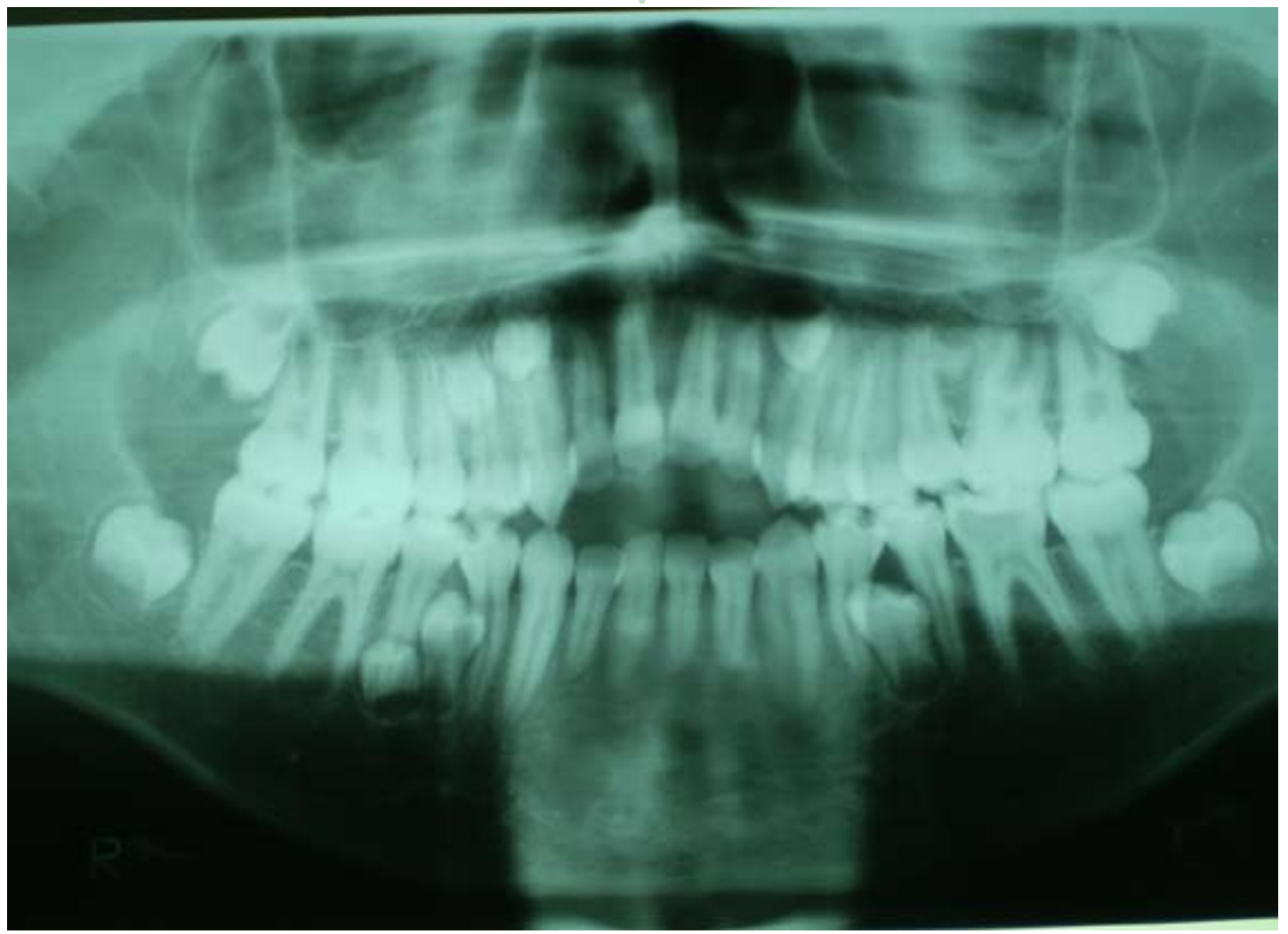

Figura 1: Radiografia Panorâmica diagnosticando os supranumerários

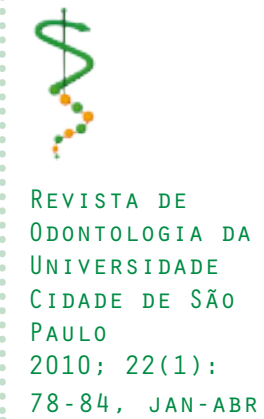


ALMEIDA TE SAA VEDRA JUNIOR $S$ KAWAKAMI PY

PALIS CA MARIANI $P B$ DOTTORE AM

HIPERDONTIA: RELATO DE CASO COM 8 ELEMENTOS SUPRANUMERÁRIOS

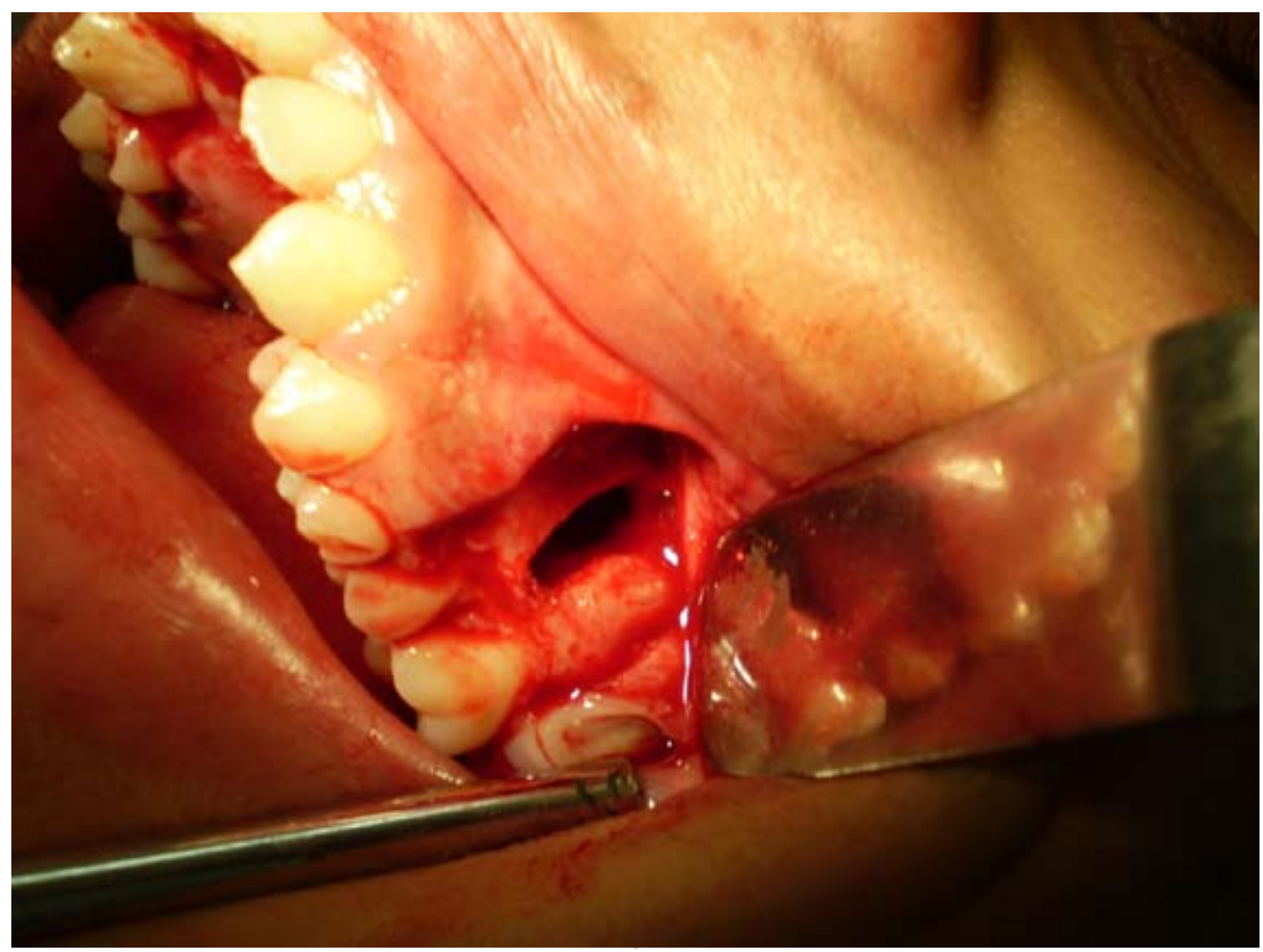

Figura 2: Loja óssea após remoção de supranumerário do lado esquerdo.

em exames radiográficos de rotina (Urena relato de caso clínico de um paciente que e Harfin ${ }^{10}$ 2001).

A proposta deste trabalho é realizar um se apresentou com oito supranumerários (sete inclusos e um erupcionado) e um to-

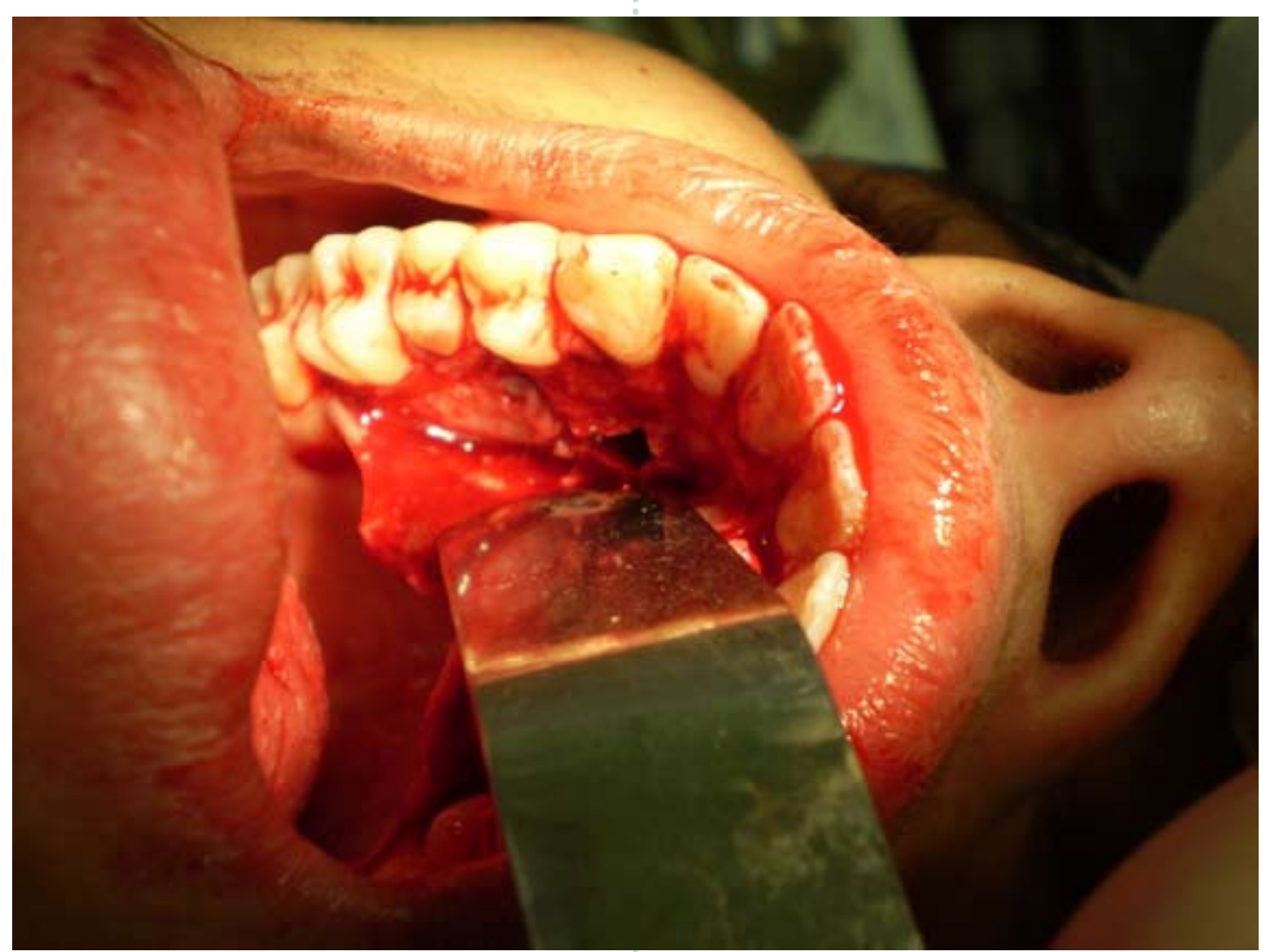

Figura 3: Acesso em palato para remoção de supranumerário. 


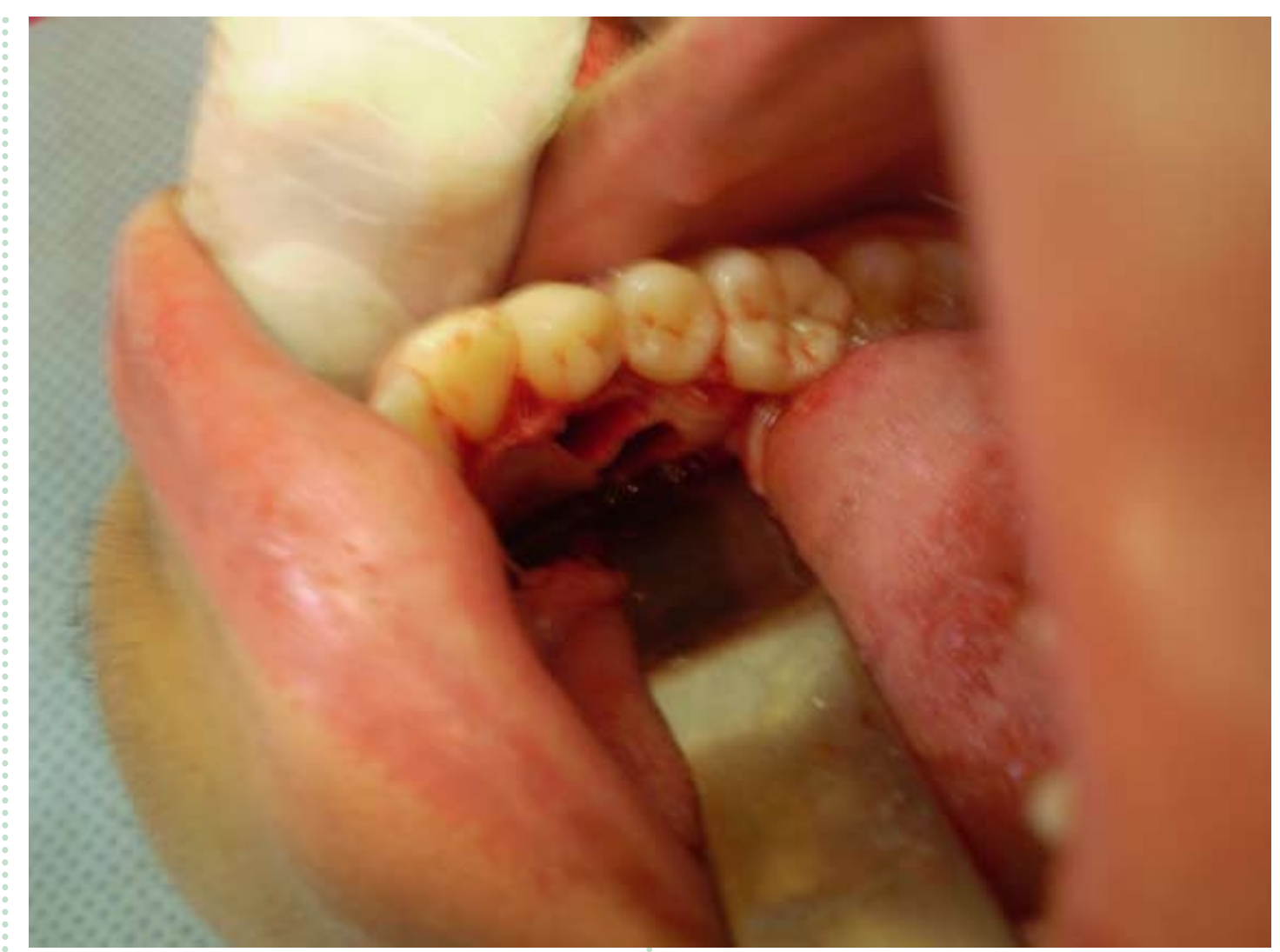

Figura 4: Loja óssea após exodontias de supranumerários mandibulares.

tal de doze inclusões.

$$
\text { RELATO DE CASO }
$$

Paciente L. H. S., gênero masculino, 16 anos de idade, pardo, foi encaminhado ao Serviço de Cirurgia Bucomaxilofacial do Hospital de Urgências de Guarulhos no
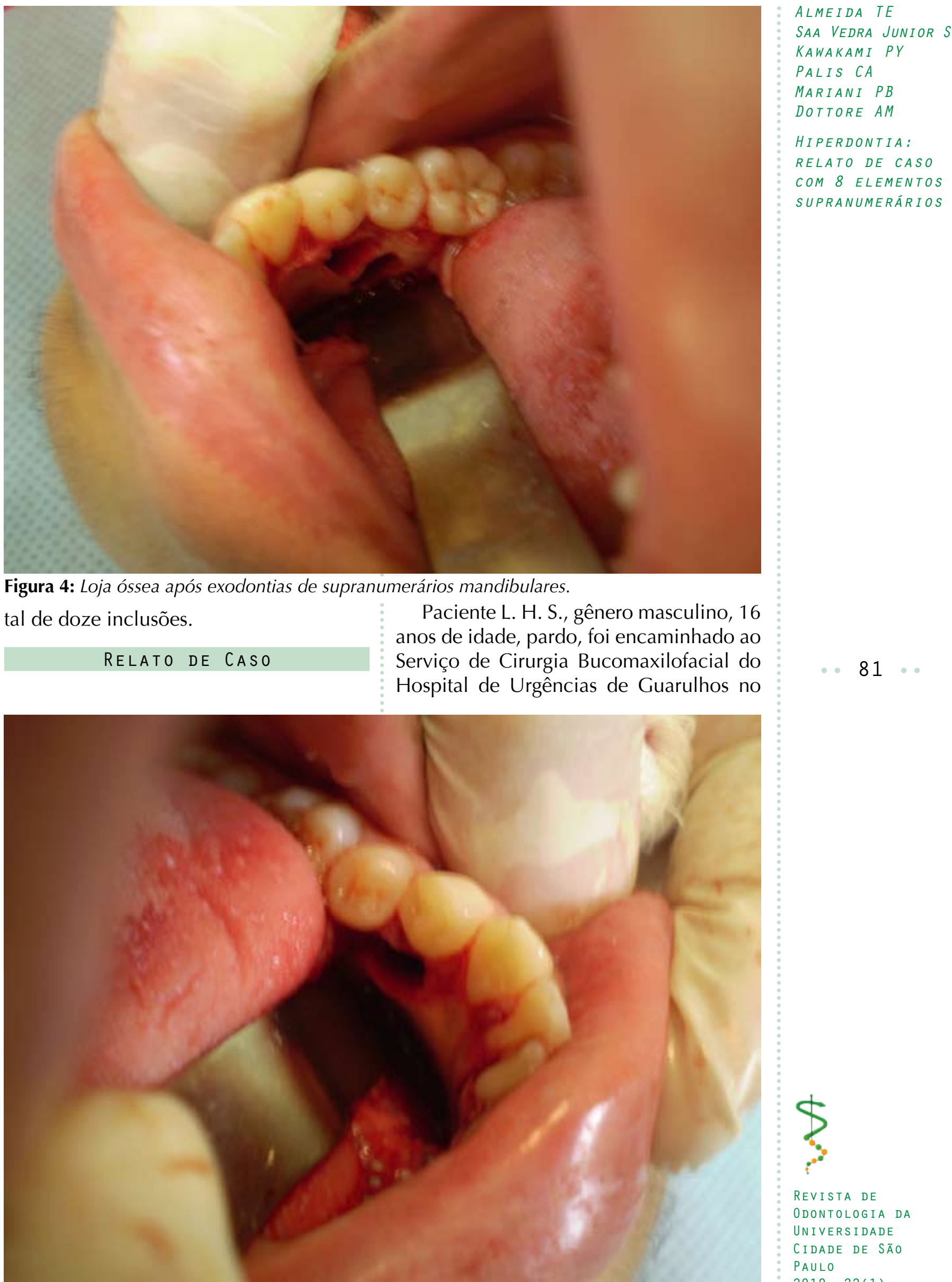

Figura 5: Loja óssea após exodontia de supranumerário mandibular.

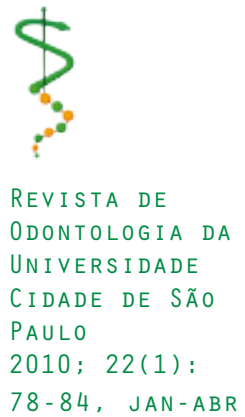


ALMEIDA TE SAA VEDRA JUNIOR $S$

KAWAKAMI PY

PALIS CA

MARIANI PB

DOTTORE AM

HIPERDONTIA: RELATO DE CASO COM 8 ELEMENTOS SUPRANUMERÁRIOS estado de São Paulo por sua ortodontista que havia diagnosticado a presença de elementos supranumerários nas radiografias solicitadas na documentação ortodôntica (Figura 1). Além da radiografia panorâmica foram realizadas radiografias oclusais e periapicais. Essas radiografias revelaram a presença de sete supranumerários inclusos, sendo quatro na maxila e três na mandíbula e um pré-molar supranumerário erupcionado ("terceiro pré-molar").

Após a anamnese e exame clínico verificou-se oportunidade cirúrgica. O planejamento cirúrgico compreendeu três etapas com intervalos de quinze dias entre elas: na primeira ocorrendo as exodontias dos supranumerários maxilares; na segunda removendo-se os supranumerários mandibulares e a terceira com a exodontia dos terceiros molares inclusos.

As três cirurgias foram realizadas com anestesia local e o anestésico utilizado foi o Cloridrato de Lidocaína a 30mg/ml com hemitartarato de norepinefrina a $0,04 \mathrm{mg} /$ ml. Já a prescrição foi de amoxicilina 500mg de 8/8 horas por sete dias via oral, diclofenaco sódico 50mg de 8/8 horas por cinco dias via oral e dipirona sódica 500mg de 6/6 horas, se apresentasse dor. Em todos os procedimentos houve antissepsia intraoral com clorexedina e colocação de campos estéreis.

$\mathrm{Na}$ primeira cirurgia realizou-se uma incisão mucoperiostal sulcular em palato, e outro retalho mucoperiostal tipo NovakPeter em região vestibular próxima ao elemento 26. Foram realizadas osteotomias com alta rotação, utilizando-se brocas esféricas cirúrgicas com posterior remoção dos elementos supranumerários, incluindo-se o elemento erupcionado (figuras 2 e 3). Já na segunda etapa do tratamento, a incisão mucoperiostal foi realizada em região sulcular lingual, após correta divulsão, foram realizadas osteotomias com alta rotação com brocas esféricas cirúrgicas e posterior remoção dos elementos (figuras 4 e 5). Por fim, procedeu-se à remoção dos $3^{\circ s}$ molares inclusos. Em todos os procedimentos cirúrgicos a síntese foi realizada com fio de sutura mononylon 4,0 (Figura 6).

$$
\text { D I SCUSSÃO }
$$

O tratamento cirúrgico dos dentes supranumerários sempre foi um consenso

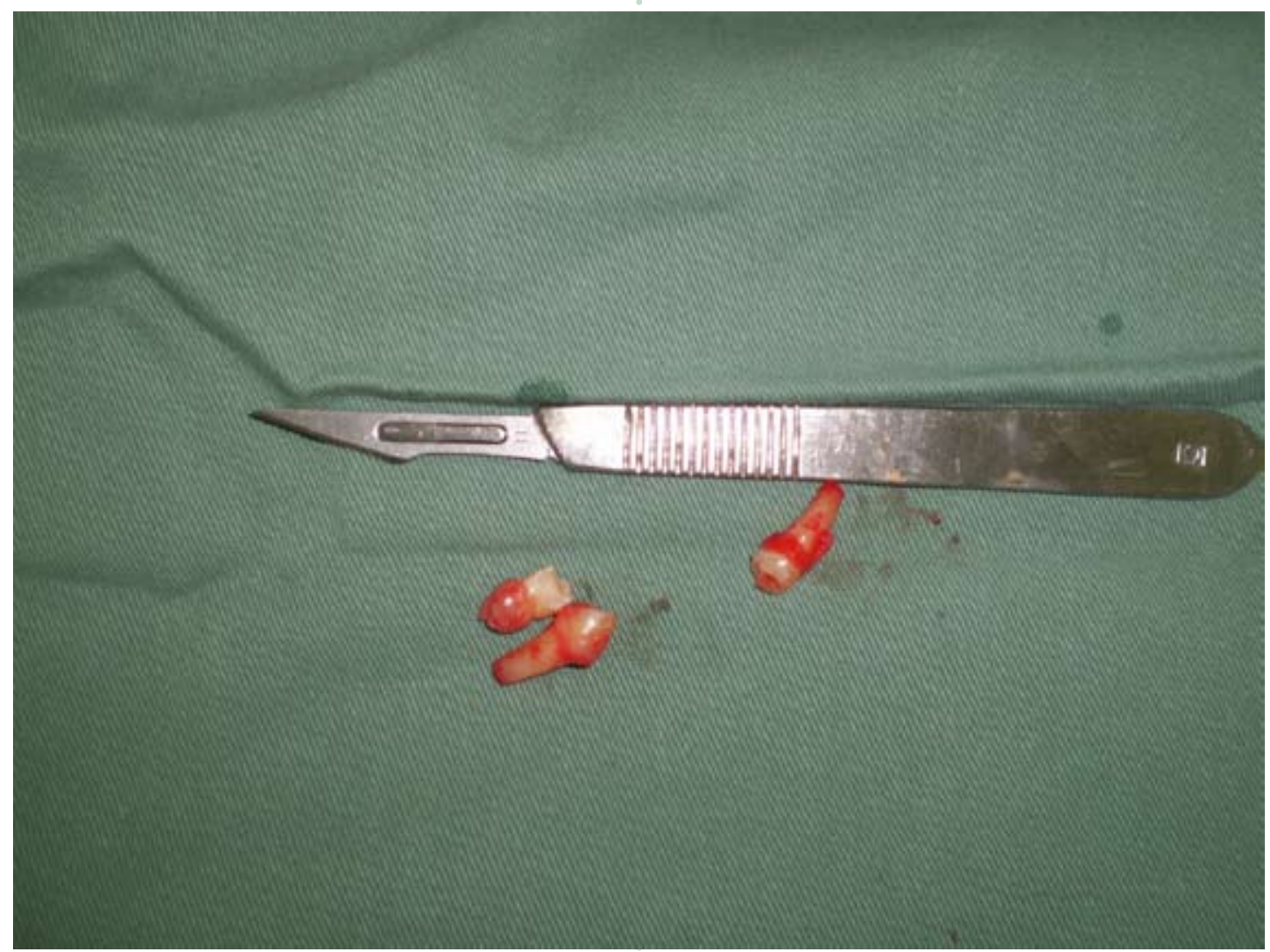

Figura 6: Dentes supranumerários removidos. 
na literatura científica, mas existe muita controvérsia quando se discute o momento ideal para se proceder a cirurgias. Muitos autores recomendam a extração dos supranumerários concomitantemente com as exodontias dos terceiros molares, caso obviamente estes dentes tenham indicação de extração (Leonard e Barbato ${ }^{11}$ 2004, Scanlan e Hodge ${ }^{12}$ 1997). Esses autores estão de acordo com o planejamento cirúrgico indicado para o caso.

Por outro lado, a grande maioria dos autores recomenda que os elementos supranumerários devam ser controlados e removidos posteriormente, quando as raízes estiverem mais desenvolvidas, evitando-se assim danos a estruturas adjacentes e permitindo uma melhor regeneração óssea (Breckton e Jones ${ }^{13}$ 1991, Kocaderili et al..$^{14}$ 1994, Rubenstein et al. ${ }^{15}$ 1991). Isso não está de acordo com Peterson et al. ${ }^{16}$ (2000) que recomendam a extração de todo e qualquer incluso assim que for diagnosticado. Desse modo não parece lógico aguardar para realizar as exodontias, pois parece óbvio que na maioria das vezes, quanto menor for a raiz, menor serão as osteotomias. Já com relação aos danos as estruturas adjacentes, deve-se lembrar sempre que, dependendo da posição e da necessidade da extração, haverá o risco de se lesionar estruturas nobres podendo levar a sequelas, independentemente do momento que se optar pelo procedimento operatório. Por fim alguns autores afirmam que os dentes associados a elementos inclusos estão mais sujeitos a terem problemas periodontais (Petersen et al. ${ }^{16}$ 2000).

Com relação às indicações das exodontias de supranumerários, pode-se situar o atraso da erupção dos dentes permanentes, a formação de cistos dentígeros, erupção dentro da cavidade nasal (Amaral e
Santos ${ }^{17}$ 1996). Também a literatura menciona como indicação o planejamento ortodôntico, pois esses dentes interferem nas movimentações ortodônticas, como afirmado por Urena \& Harfin ${ }^{10}$ (2000). Indicação esta que vai de acordo com o caso relatado neste trabalho.

O diagnóstico dos elementos supranumerários, quando erupcionados, é clínico, mas quando estão inclusos, o diagnóstico ocorre em exames de rotina, já que na maioria das vezes são assintomáticos (Koo et al. ${ }^{18}$ 2002, Spauge ${ }^{6}$ 1973). A literatura recomenda exames radiográficos rotineiros em crianças para que o diagnóstico seja precoce (Amaral e Santos ${ }^{17}$ 1996) Por outro lado, alguns autores recomendam tomografias computadorizadas para diagnóstico e posicionamento dos supranumerários (Bertolo et al. ${ }^{1}$ 2007). O uso da tomografia computadorizada parece desnecessário para a localização desses elementos dentários, pois as técnicas radiográficas convencionais são suficientes. No caso apresentado, o paciente teve seu diagnóstico através de exames de rotina, já que iria iniciar o tratamento ortodôntico.

\section{CONCLUSÕES}

Os dentes supranumerários são anomalias dentárias relativamente comuns, e sua prevalência varia de $0,1 \%$ a $3,8 \%$.

O caso apresentado é raro, pois apresenta supranumerários, tanto na maxila quanto na mandíbula, totalizando oito supranumerários, sendo sete inclusos e um já erupcionado.

Na maioria das vezes, o diagnóstico se faz através de radiografias de rotina, como no caso apresentado.

O tratamento é eminentemente cirúrgico, não havendo consenso na literatura o melhor momento para realizá-lo.
ALMEIDA TE

SAA VEDRA JUNIOR S

KAWAKAMI PY

PALIS CA

MARIANI PB

DOTTORE AM

HIPERDONTIA:

RELATO DE CASO

COM 8 ELEMENTOS

SUPRANUMERÁRIOS

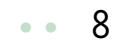

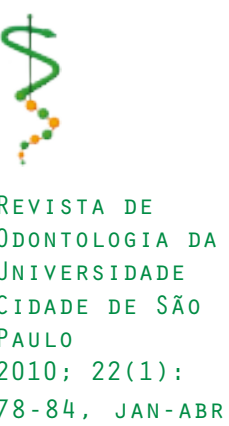


ALMEIDA TE SAA VEDRA JUNIOR S

KAWAKAMI PY

PALIS CA

MARIANI PB

DOTTORE AM

HIPERDONTIA:

RELATO DE CASO

COM 8 ELEMENTOS

SUPRANUMERÁRIOS

\section{REFERENCIAS}

1. Bertollo MR, Batista PS, Cançado RP; Oliveira HW, Oliveira MG. Dente supranumerário tomografia computadorizada método de localização - relato de caso clínico. Rev Odonto Ciência 2000 Ago; 15(2): 97-109.

2. Scheiner MA, Sampson WJ. Supranumerary teeth: a review of the literature and four cases reports. Aust Dent J 1997 Jun; 42(3):160-5.

3. Campos LM, Silva SREP, Imparato JCP, Pinheiro SL. Dente supranumerário rudimentar relato de caso. J BrasClin Odontol Int 2002 mar/abr; 6(32): 129-32.

4. Bhaskar SN. Patologia bucal. 4 ed.: São Paulo: Artes Médicas; 1976. p.61 65.

5. Shafer WG, Hine MK, Levy BM. Tratado de patologia bucal. $4^{\circ}$ ed Rio de Janeiro: Guanabara Koogan, 1987. 837p.

6. Spauge J.D. Oral Pathology. St Louis: Mosby Co., 1973.

7. Duarte CA, Gomes MF. Cuidado cirúrgico periodontal na exodontia de supranumerário incluso: relato de caso. $\operatorname{Rev} A B O 1995$ Jan; 2(6): 438-40.

8. Pindborg JJ. Pathology of the dental hard tissues, Munksgaard: Copenhagen, 1970.

9. Yusof WZ. Non-syndrome multiple supernumerary teeth: literature review. J Can Dent Assoc 1990 Feb; 56(2):147-9.

10. Urena A, Harfin J. Tratamento atípico com supranumerários: uma problemática para pensar y resolver. Sociedad Argentina de Ortodontia 2001 May-Jun; 65(129): 31-9.

11. Leonard R, Barbato E. A late developing supernumerary premolar. J Clin Orthod 2004 Jun; 38(6): 331-2.

12. Scanlan PJ, Hodges SJ. Supernumerary premolar teeth in siblings. Br Orth Soc 1997 Nov; 24(4): 297-300.

13. Breckton JJW, Jones SP. Late forming supernumeraries in the mandibular premolar region. Brith J Orthd 1991 Nov; 18(4):329-31.

14. Kocadereli I, Ciger S, Cakirer B. Late-forming supernumeraries in the premolar regions. J Clin Orthod 1994 Mar; 28(3):143-4.

15. Rubenstein LK, Lindauer SJ, Isaacson RJ, Germane N. Development of supernumerary premolars in a orthodontic population. Oral Surg Oral Med Oral Pathol 1991 Mar; 71(3): 392-5.

16. Peterson LJ, Ellis E, Hupp JR, Tucker MR. Cirurgia oral e maxilofacial contemporânea, $3^{\circ}$ ed. Rio de Janeiro: Guanabara Koogan; 2000.772p.

17. Amaral MAT, Santos MEO. Má oclusão causada por dentes extranumerários: apresentação de um caso clínico. Rev Bras. Odontol 1996 jan-fev; 53(1): 2-4.

18. Koo S, Salvador PS, Ciuffi Junior J, Silva Junior AR. Bilateral maxillary fourth molars an a supernumerary tooth in maxillary canine region a case report. South African Dental Journal 2002 Oct; 57(10):404-6.

Recebido em: 28/09/2009

Aceito em: 11/01/2010 